\title{
A Influência da Ponderação na Avaliação do Grau de Criticidade em Edificações de Múltiplos Pavimentos Via Inspeção Predial
}

The Influence of Weighting Coefficient in the Evaluation of the Critical Degree in Multi-Storey Buildings Via Inspection

La influencia de la ponderación en la evaluación del grado de criticidad en edificios de pisos múltiples vía la inspección de edificios

PANTOJA, João da Costa ${ }^{1}$ MOURA, Sara Prado Novais ${ }^{2}$

CAIED, Samir ${ }^{3}$ VARUM, Humberto ${ }^{4}$

1Programa de Pós-Graduação - PPG-FAU, Universidade de Brasília, Brasília, Brasil. joaocpantoja@gmail.com ORCID: 0000-0002-0763-0107

2Programa de Pós-Graduação - PPG-FAU, Universidade de Brasília, Brasília, Brasil. sarapnm@gmail.com ORCID: 0000-0001-9398-1343

3Programa de Pós-Graduação - PPG-FAU, Universidade de Brasília, Brasília, Brasil. samircaied@gmail.com ORCID: 0000-0003-4914-7508

${ }^{4}$ Departamento de Engenharia Civil, Faculdade de Engenharia, Universidade do Porto, Porto, Portugal. hvarum@fe.up.pt ORCID: 0000-0003-0215-8701 


\title{
Resumo
}

O objetivo deste artigo é analisar e discutir o uso de variáveis de ponderações sobre os elementos de uma edificação de múltiplos pavimentos com base em resultados da inspeção. Para este estudo, foi realizada uma comparação entre: a ponderação de criticidade a partir da média aritmética, a ponderação com base nos níveis de criticidade, porém este afetado pelo custo de recuperação e por importância do elemento. Essa discussão é de grande valia, pois os resultados apresentados poderão nortear as decisões dos proprietários e gestores sobre como manejar a verba orçamentária, sobre as obras de reparação e de correção das patologias. O estudo de caso foi realizado em uma edificação residencial tipo pilotis, localizada na cidade de Brasília, construída em 1973, em concreto armado, composta por 6 pavimentos. Na coleta de dados foi feita a inspeção predial com registro fotográfico e croquis, e ensaios semi-destrutivos. Verificou-se que utilizando a norma holandesa para inspeção predial, com base nos níveis de criticidade, a edificação teve seu grau de criticidade em todas as formas de ponderação classificados em um estado geral como "razoável". Outros critérios também podem ser utilizados, aplicados e comparados em trabalhos futuros.

Palavras-Chave: Norma holandesa; Inspeção predial; Níveis de criticidade; Custos de recuperação; Estudo de caso.

\begin{abstract}
The purpose of this article is to analyze and discuss the use of weighting variables on the elements of a multi-storey building based on inspection results. For this study, a comparison was made between: the criticality weighting from the arithmetic mean, the weighting based on the criticality levels, but this is affected by the cost of recovery and the importance of the element. This discussion is of great value, as the results presented may guide the decisions of the owners and managers on how to manage the budgetary budget, on the works of repair and correction of pathologies. The case study was carried out in a pilotis-type residential building, located in the city of Brasília, built in 1973, in reinforced concrete, consisting of 6 floors. In data collection, building inspection was done with photographic record and sketches, and semi-destructive tests. It was found that using the Dutch standard for building inspection, based on the levels of criticality, the building had its degree of criticality in all forms of weighting classified in a general state as "fair". Other criteria can also be used, applied and compared in future works.
\end{abstract}

Key-Words: Dutch standard; Building inspection; Criticality levels; Recovery costs; Case study.

\section{Resumen}

El propósito del artículo es analizar y discutir el uso de variables de ponderación en los elementos de un edificio de varios pisos en función de los resultados de la inspección. Para este estudio se realizó una comparación entre: ponderación de criticidad basada en la media aritmética, ponderación basada en niveles de criticidad, pero este afectado por el costo de la recuperación y la importancia del elemento. Esta discusión es de gran valor ya que los resultados presentados pueden guiar las decisiones de los propietarios y gerentes sobre cómo administrar el presupuesto, sobre la reparación y corrección de patologías. El estudio de caso se realizó en un edificio residencial tipo pilotis, ubicado en la ciudad de Brasilia, construido en 1973, en hormigón armado, de 6 pisos. En la recopilación de datos, la inspección del edificio se realizó con registros fotográficos y croquis, y ensayos semi-destructivos. Se descubrió que, utilizando la norma holandesa para la inspección de edificios, basada en los niveles de criticidad, el edificio tenía su grado de criticidad en todas las formas de ponderación clasificadas, en general, como "razonables". También se pueden usar, aplicar y comparar otros criterios en trabajos futuros.

Palabras clave: Norma holandesa; Inspección de edificios; Niveles de criticidad; Costos de recuperación; Estudio de caso 


\section{Introdução}

As edificações sofrem degradação ao longo da sua vida útil, quer seja pelo seu envelhecimento natural e/ou por ações externas acidentais de origem humana ou natural. Essas alterações provocam anomalias que podem comprometer o desempenho das funções para que foram concebidos, e podendo até colocar em risco a segurança dos edifícios.

Para recuperação de um edifício, é necessário avaliar o seu estado de conservação, pois, conforme sustentado em Natário (2016), uma manutenção periódica é fundamental para minimizar a degradação de edifícios e evitar necessidade de reabilitação profunda na edificação. No documento Horner (1997) refere-se que a manutenção predial pode ser desenvolvida em três direções: corretiva, preventiva e baseada em condições. A manutenção corretiva é caracterizada por serviços que demandam ação ou intervenção imediata com o objetivo de evitar a interrupção do uso dos sistemas, elementos ou componentes das edificações, ou para evitar riscos ou prejuízos pessoais e/ou patrimoniais aos usuários ou proprietários NBR 5674 (ABNT, 2012). Ainda no documento NBR 5674 (ABNT, 2012), refere-se que uma manutenção preventiva é caracterizada pela realização de um conjunto de ações programadas com antecedência, priorizando as solicitações dos usuários, estimativas de durabilidade dos sistemas, elementos ou componentes das edificações em uso, gravidade e urgência, e relatórios de verificações periódicas. Segundo o Comité Europeu de Normalização (CEN, 2001), a manutenção baseada nas condições é definida como manutenção preventiva fundamentada no desempenho e/ou monitoramento de parâmetros e nas ações imediatas.

Como evidenciado em Moura (2014), hoje em dia existem muitas metodologias de avaliação do estado de conservação dos edifícios, e estas são cada vez mais valorizadas como ferramentas inteligentes que podem ser utilizadas no auxílio à tomada de decisão por parte das entidades gestoras do património. Neste artigo estuda-se a norma holandesa de inspeção predial, e aplica-se a um caso de estudo, com o objetivo de avaliar o estado de conservação de edifícios em todas as demandas.

A norma holandesa para inspeção predial foi definida por forma a poder ser utilizada em todos elementos de uma edificação. A realização da avaliação com a aplicação dessa norma conduz a uma real descrição do estado de conservação do objeto avaliado.

Para Pedro et al (2012) as ponderações são aquelas que definem a importância relativa de cada elemento funcional na avaliação global. No trabalho Pedro et al (2012) os autores apresentam uma comparação entre três métodos de avaliação do estado de conservação dos edifícios. Nestes métodos são aplicados diferentes tipos de ponderações que foram utilizadas baseadas na estrutura de custos de um edifício e na importância dos elementos.

Para o presente artigo, foram aplicados três modos de ponderação na norma holandesa para inspeção predial. A primeira a ser estudada foi a ponderação por média aritmética (PMA) que define pesos iguais para todas famílias. A segunda foi a ponderação em relação aos custos (PRC), que foi aplicada o peso de cada elemento conforme o custo de recuperação. E a terceira é a aplicação da ponderação em relação à importância (PRI) definida pelos vistoriadores e os moradores da prioridade em análise. Por fim, foi realizada uma comparação entre os resultados obtidos por cada um dos métodos de ponderação usados.

Os dados para este trabalho foram obtidos por meio de vistoria no local, inspeções visuais com registros fotográficos dos defeitos encontrados no local, croquis e ensaio de aderência da cerâmica. Com os levantamentos realizados na construção foi aplicado o método da Norma Holandesa para inspeção predial, posteriormente com os valores encontrados foi aplicado três formas de ponderação para o cálculo do grau de criticidade de cada família e avaliar as diferenças entres elas. 


\section{Norma Holandesa para Inspeção Predial - NEN 2767}

Para a análise dos dados encontrados foi aplicado o método da Norma Holandesa para suporte à inspeção predial, que é utilizado para avaliação do estado de conservação de edifícios como informado pela NEN 2767 (2006) e, de acordo com Vilhena (2011), tem apenas a função de identificar as anomalias e a sua qualificação enquanto elementos potenciadores de degradação da funcionalidade do elemento construtivo. Como argumentado por Pitt (1997), uma categoria de condições para ser efetiva é essencial que as escalas sejam claramente definidas e que facilite a confiabilidade dos dados que foram obtidos. Nessa norma, é utilizada a escala de seis de pontos, categorizando 1 a melhor condição possível e 6 o pior cenário, o que significa que o componente já deveria ter sido substituído, como demonstrado na Tabela 1. Para este artigo, optou-se por trabalhar com a parametrização dos valores da norma para melhor compreensão. Assim, os valores variam de 0 a 1.

Tabela 1: Classificação de condição.

\begin{tabular}{l|l|l}
\hline $\begin{array}{l}\text { Classificação da } \\
\text { Condição }\end{array}$ & $\begin{array}{l}\text { Classificação da } \\
\text { Condição (Parametrizada) }\end{array}$ & $\begin{array}{l}\text { Descrição Geral } \\
\text { da Condição }\end{array}$ \\
\hline 1 & 0,17 & Excelente \\
2 & 0,33 & Bom \\
3 & 0,50 & Razoável \\
4 & 0,70 & Ruim \\
5 & 0,87 & Grave \\
6 & 1,00 & Intolerável \\
\hline \multicolumn{2}{|c}{ Fonte: NEN 2767 (2006) }
\end{tabular}

Segundo Straub (2009)0, a norma holandesa para inspeção predial se inicia com a avaliação dos defeitos da edificação, em seguida é estabelecida as condições de parâmetros como: importância dos defeitos, intensidade dos defeitos e extensão dos defeitos. A extensão e a intensidade de um defeito combinado com a importância levam a uma classificação da condição, como está demonstrado na Figura 1.

Figura 1: Processo de avaliação de condição.

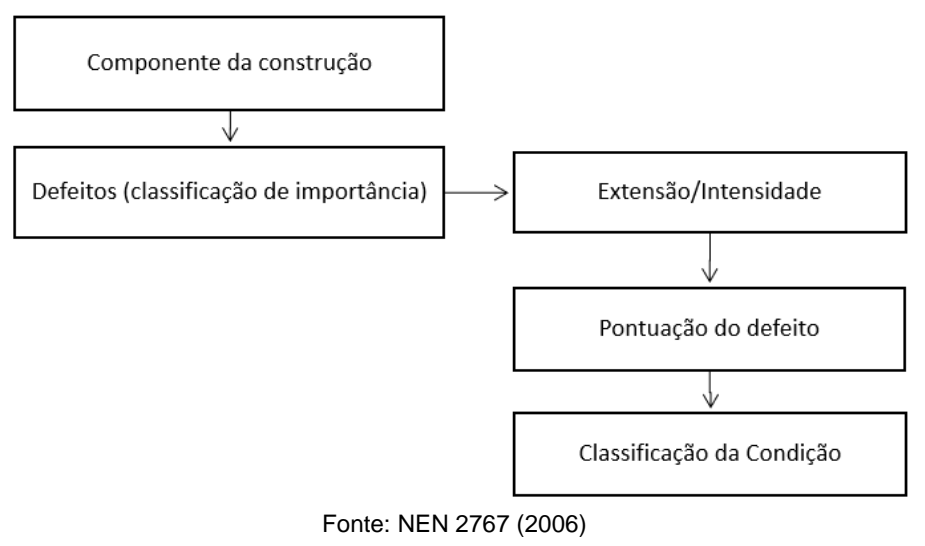

$\mathrm{Na}$ análise da edificação realizou-se uma divisão dos componentes da construção em elementos com a finalidade de facilitar a avaliação visual, o que permitiu uma classificação definida e hierárquica. A hierarquização dos componentes influencia diretamente a classificação da importância dos defeitos, já que este indica em que medida afeta o funcionamento dos componentes do edifício.

A classificação da importância dos defeitos dos elementos é dividida em leve, séria e críticos, sendo os defeitos críticos aqueles que ameaçam significativamente a função do componente da construção. Estes são, geralmente, defeitos intrínsecos ao material, defeitos que ameaçam a estrutura do edifício e defeitos funcionais, e, são aqueles que já estão associados a uma falha. Os defeitos graves tendem a 
prejudicar, ou alterar, gradualmente o desempenho dos componentes do edifício. Os defeitos nos acabamentos são classificados como defeitos leves (STRAUB, 2009).

A intensidade dos defeitos tem uma forte influência na condição dos componentes do edifício. Aquela está relacionada com o processo de degradação e seu grau de desenvolvimento, por exemplo, efeitos de envelhecimento que são defeitos intrínsecos do material e defeitos envolvendo a superfície do material que desenvolvem-se durante um certo período e ocorrerão em várias intensidades, mas há defeitos causados por ações extremas, naturais ou de origem humana que ocorrem apenas em um estágio da existência da obra. A classificação da intensidade dos defeitos é dividida em três níveis, nomeadamente: baixa (quando o defeito é dificilmente visível), média (defeito progredindo) e alta (defeito não pode progredir mais) (STRAUB, 2009).

A extensão de defeitos é referente à área do elemento que é afetado, e é um fator muito importante para avaliar a condição do elemento. A sua divisão é feita em cinco classes, de quando o defeito está no estágio inicial até quando ele já ocorre com mais frequência (STRAUB, 2009; VILHENA, 2011).

A extensão e a intensidade combinadas com a importância do defeito levam a uma classificação da condição do elemento, como cita Straub (2009). Os defeitos críticos, "graves" e "leve" alterando de baixa a alta com os valores parametrizados variam de 0,17 a 1 .

Após encontrar classificação da condição de cada elemento é calculada a média para cada família e finalmente para a edificação. Para esse estudo foram realizadas a média aritmética e a ponderada, e comparam-se qual se aproxima mais da realidade do que foi encontrado no local.

\section{Estudo de Caso}

Neste ponto, apresenta-se brevemente a edificação, os resultados da aplicação da norma holandesa para inspeção predial parametrizada ponderada por média aritmética, e ponderada em relação aos custos de recuperação e apresenta-se também uma comparação entre as duas ponderações.

\subsection{Breve Descrição da Edificação}

Os estudos deste artigo foram realizados em um edifício localizado na SQS 113, Bloco A (DF, Brasil), realizado em janeiro de 2014 (Figura 2), solicitado pela comissão de obras do condomínio. Da informação recolhida no local eram evidentes patologias visíveis, confirmadas pelas queixas dos moradores.

Figura 2: Localização do Edifício SQS 113.

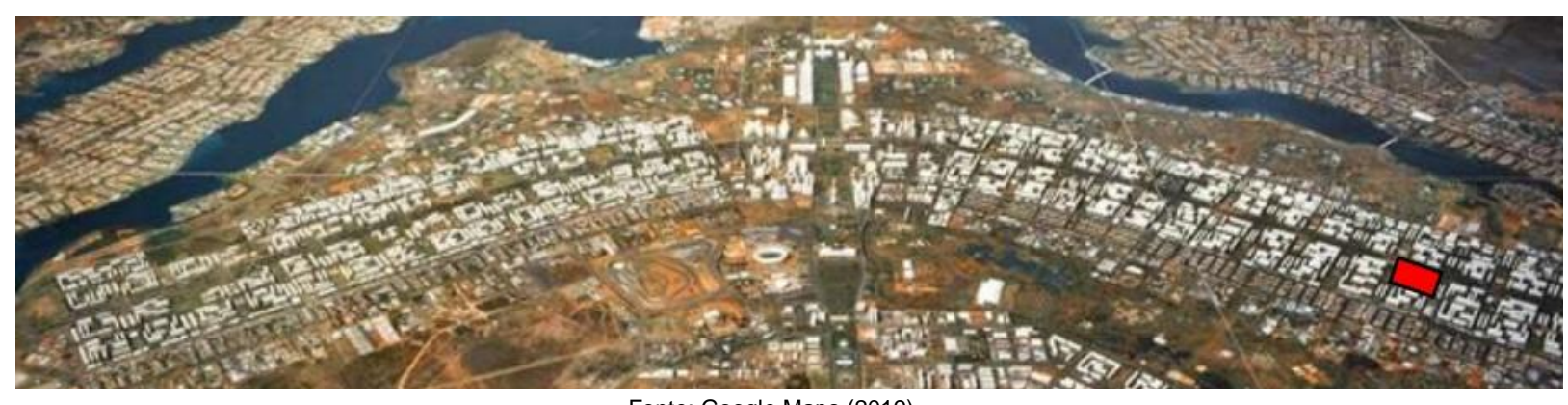

Fonte: Google Maps (2019)

A edificação, construída em 1973 em concreto armado, possui 6 pavimentos e um sistema estrutural tipo pilotis, seguindo os princípios de Lúcio Costa para o plano piloto de Brasília (Figura 3). Desde a construção, não foram realizadas intervenções significativas nas áreas comuns da edificação. $\mathrm{Na}$ inspeção, a análise do edifício focou-se em oito famílias de elementos/sistemas: os pilares do piso térreo (pilotis), as fachadas, as prumadas, as instalações hidráulicas, o subsolo, as condições de 
acessibilidade, as instalações elétricas e a cobertura.

Figura 3: Fachadas: (a) frontal; e (b) posterior.

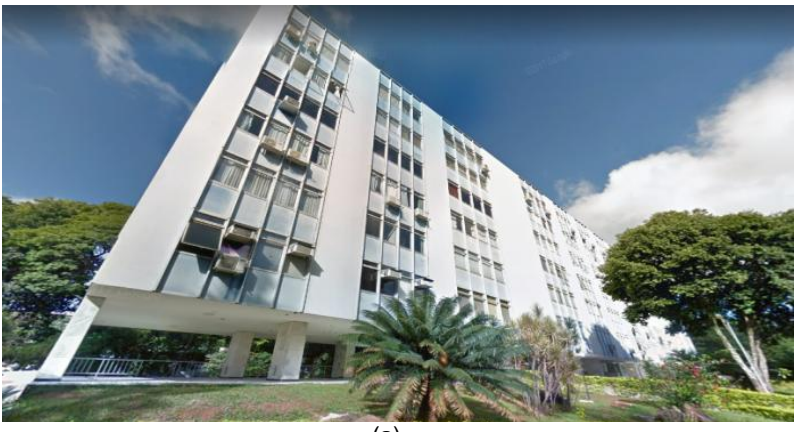

(a)

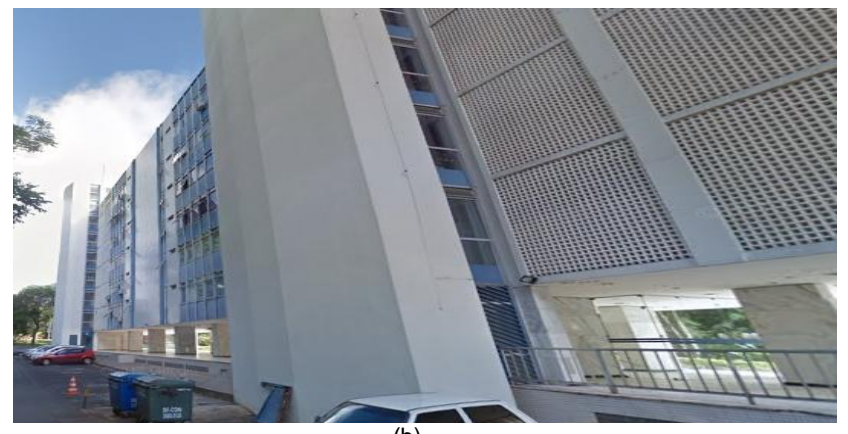

(b)

Fonte: Primeiro Autor

\subsubsection{Divisão em famílias}

Em seguida apresenta-se uma breve descrição das principais características das famílias de elementos/sistemas estudados, bem como das falhas e/ou manifestações patológicas encontradas.

\section{Pilotis}

Os pilotis possuem piso e colunas revestidos por mármore branco e o teto revestido por forro de gesso na cor branca. Os principais defeitos encontrados correspondem a um acabamento fosco e acinzentado do revestimento de mármore (Figura 4a) e a trincas no forro de gesso (Figura 4b).

Figura 4: Principais patologias ao nível do nível térreo: (a) revestimento desgastado; e (b) forro de gesso danificado.

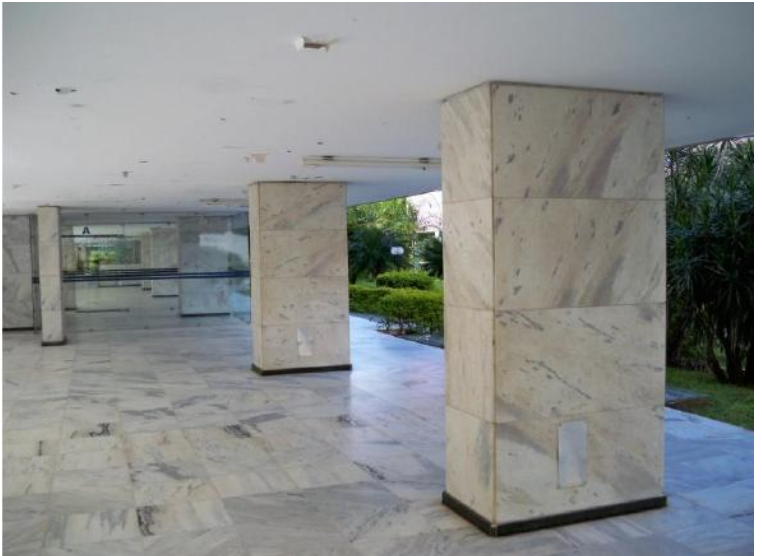

(a)

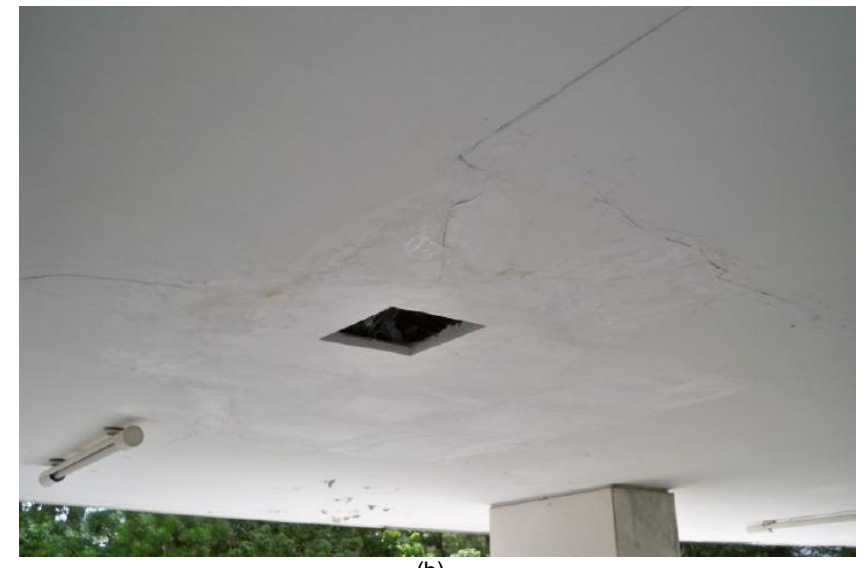

(b)

\section{Fachadas}

A fachada é revestida por peças cerâmicas e esquadrias de maxim-ar de ferro. A parte fixa da esquadria recebe um acabamento com pintura na cor azul, esta pintura já está bastante danificada pela ação das intempéries (5a). Encontram-se ainda relatos de infiltração de água das chuvas pela esquadria em alguns dos apartamentos. O revestimento cerâmico apresenta descolamento em áreas localizadas (5b). No ensaio de arranchamento cerâmico não foram diagnosticados sinais de significativa redução de desempenho. 
Figura 5: Principais patologias nas fachadas: (a) pintura na cor azul desgastada; e (b) azulejo solto.

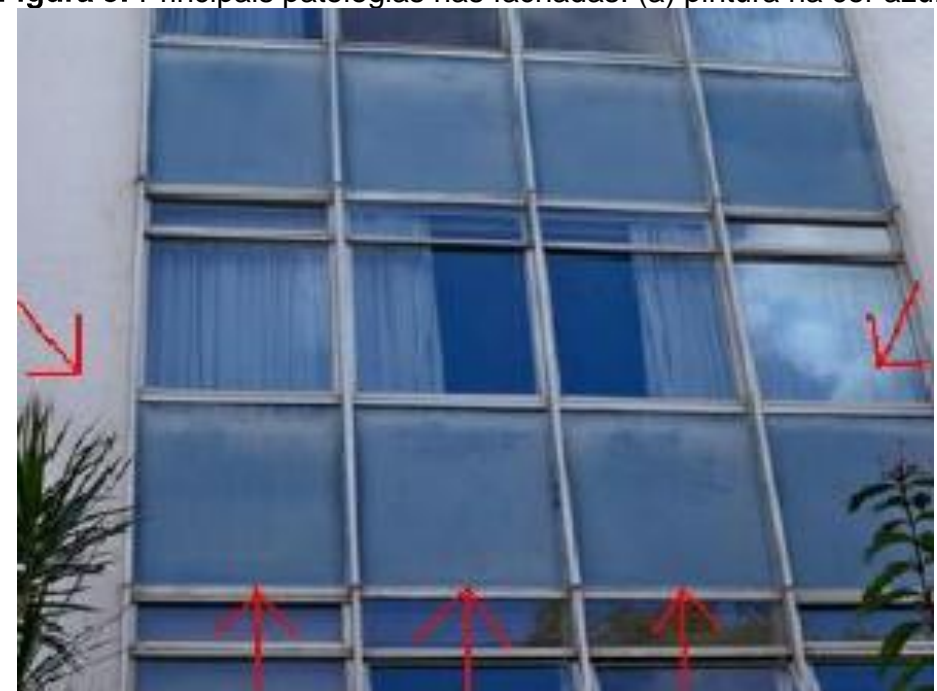

(a)

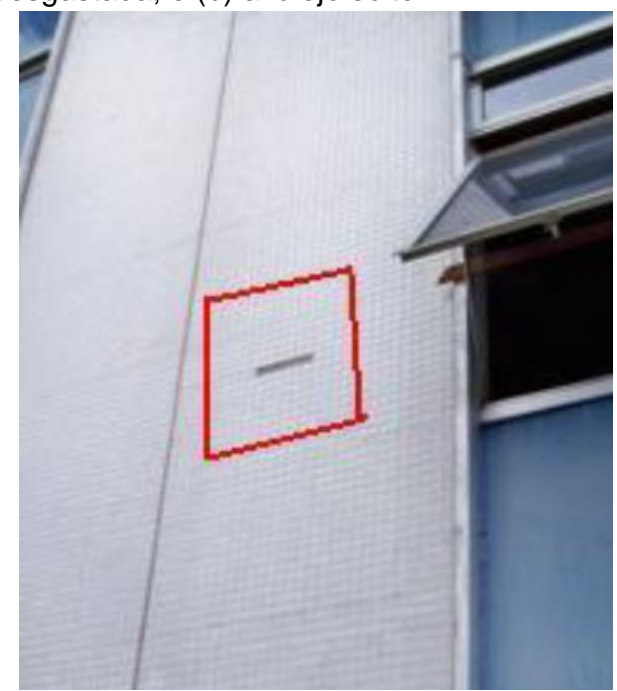

(b)

\section{Prumadas}

A família prumadas engloba as lixeiras que possuem revestimento cerâmico com soltos ou fissurados e as escadas que possuem fissuras na alvenaria perto das portas de entrada dos apartamentos (6).

Figura 6: Principais patologias nas prumadas: (a) armadura exposta; e, (b) fissuras e infiltrações.

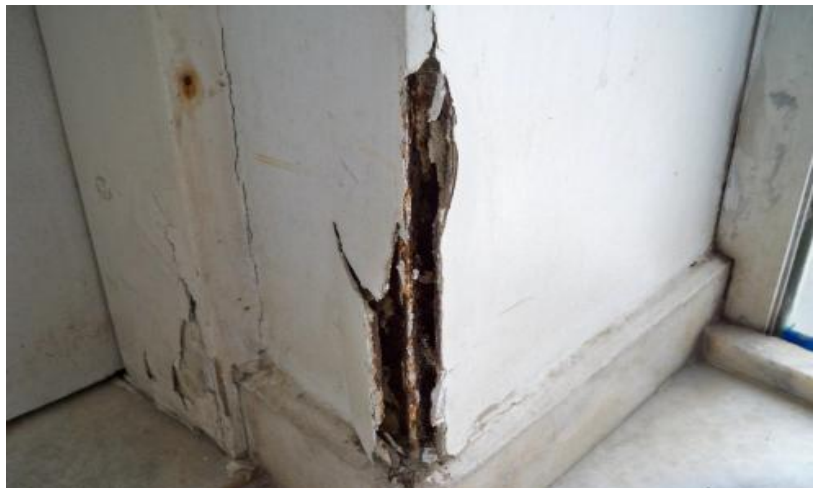

(a)

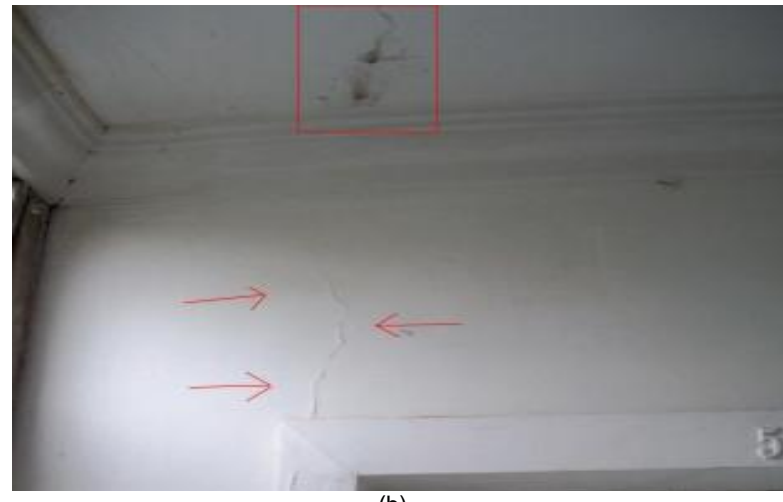

(b)

Fonte: Primeiro Autor

\section{Instalações hidráulicas}

As instalações hidráulicas são de ferro fundido. As caixas de gordura (7a) e sabão (7b) estão danificadas com rachaduras e com sinais de entupimento. Na tubulação que liga as caixas de captação de água pluvial é de material cerâmico, visualmente trincado. $O$ sistema de combate a incêndios não está devidamente sinalizado. 
Figura 7: Principais patologias nas instalações hidráulicas: (a) caixa de gordura; e (b) caixa de sabão com rachaduras.

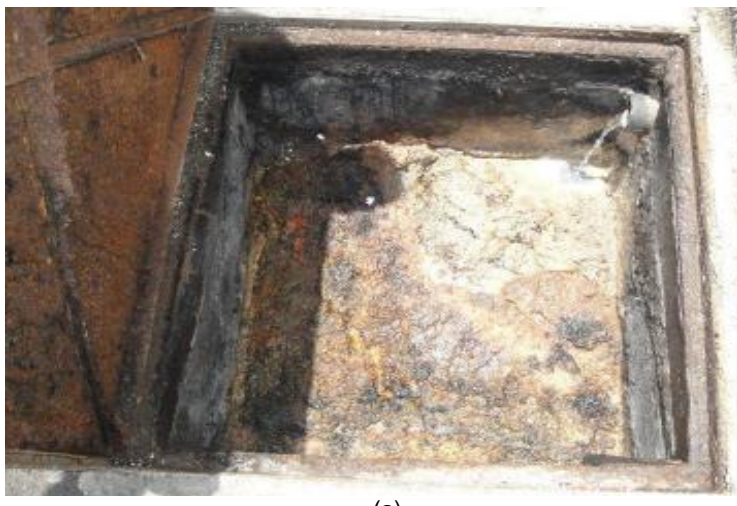

(a)

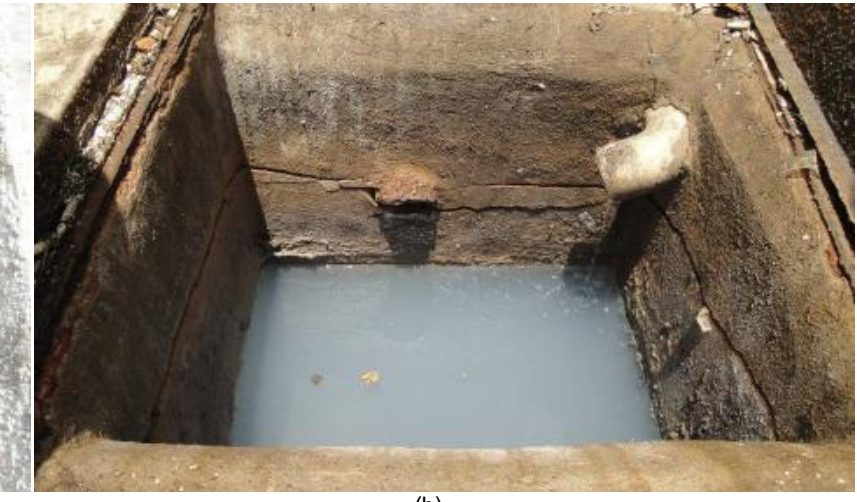

(b)

Fonte: Primeiro Autor

\section{Subsolo}

A contenção do subsolo é realizada através de uma cortina em concreto armado que está sofrendo de percolação de água em um ponto localizado, também foram encontrados focos de infiltração no quarto do zelador e na claraboia. Alguns pilares estão com suas armaduras em processo de corrosão (8a). $\mathrm{Na}$ caixa d'água inferior também foi constatada corrosão nas armaduras (8b).

Figura 8: Principais patologias nos estruturais do subsolo: corrosão (a) nas armaduras dos pilares; e, (b) na caixa d’água.

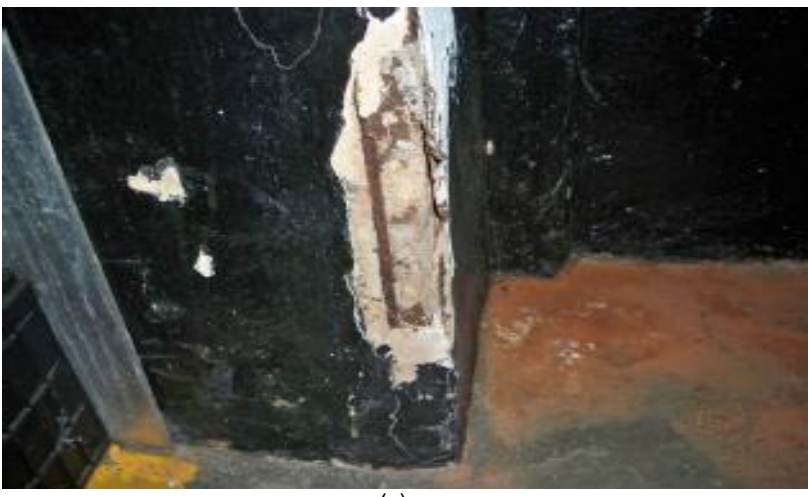

(a)

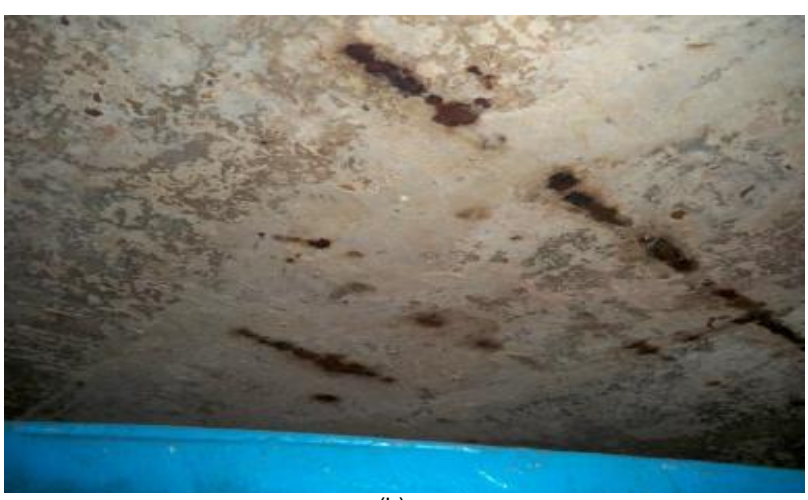

(b)

Fonte: Primeiro Autor

\section{Acessibilidade}

A edificação é anterior à primeira norma de acessibilidade (ABNT NBR 9050, 1985). Não há demarcações de vagas para veículos, existem erros de inclinações de rampa (9a), sinalização e falta de guarda-corpos e corrimãos (9b). 
Figura 9: Principais problemas de inconformidades associadas às acessibilidades da edificação: (a) rampa; e (b) escadas.

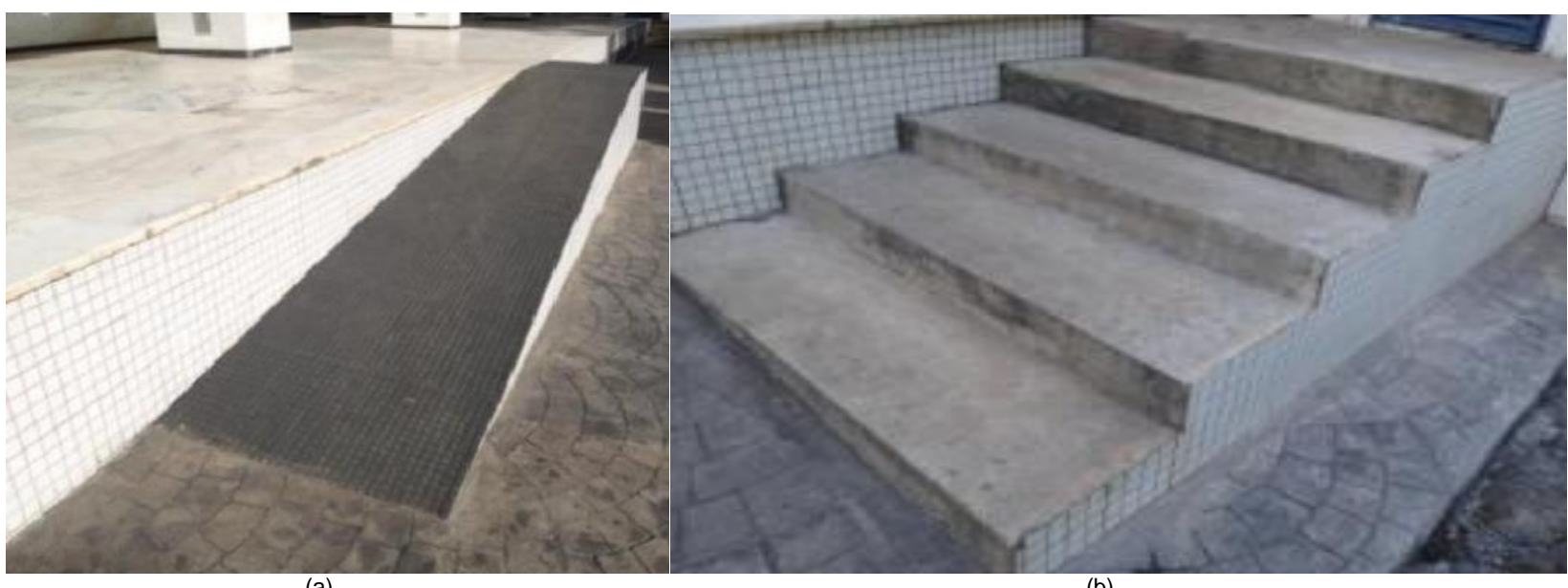

(a)

Fonte: Primeiro Autor

\section{Instalações elétricas}

O cabeamento que liga os relógios da companhia elétrica ao quadro interno dos apartamentos já foi substituído, nomeadamente os fios rígidos foram substituídos por fios flexíveis. O eletroduto está sem proteção e sujeito às águas pluviais. A referência ôhmica do SPDA está superior à mínima (10a e 10b).

Figura 10: Principais problemas associados às instalações elétricas: (a) QFL condomínio entrada; e (b) Eletroduto sem proteção.

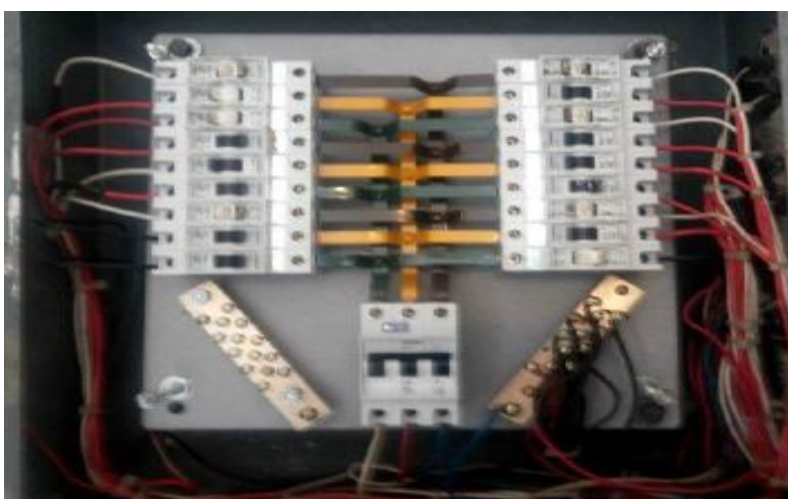

(a)

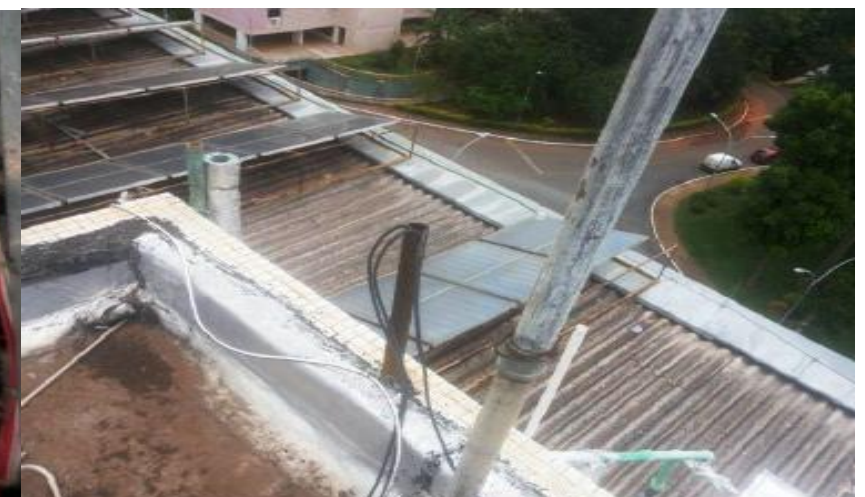

(b)

Fonte: Primeiro Autor

\section{Cobertura}

A laje é revestida por telhas onduladas de amianto. Algumas dessas telhas estão danificadas e evidenciam problemas de falta de manutenção (11). Os painéis de captação de energia solar estão em bom estado, necessitando apenas de limpeza. 
Figura 11: Principais patologias na cobertura: (a) e (b) telhas danificadas.

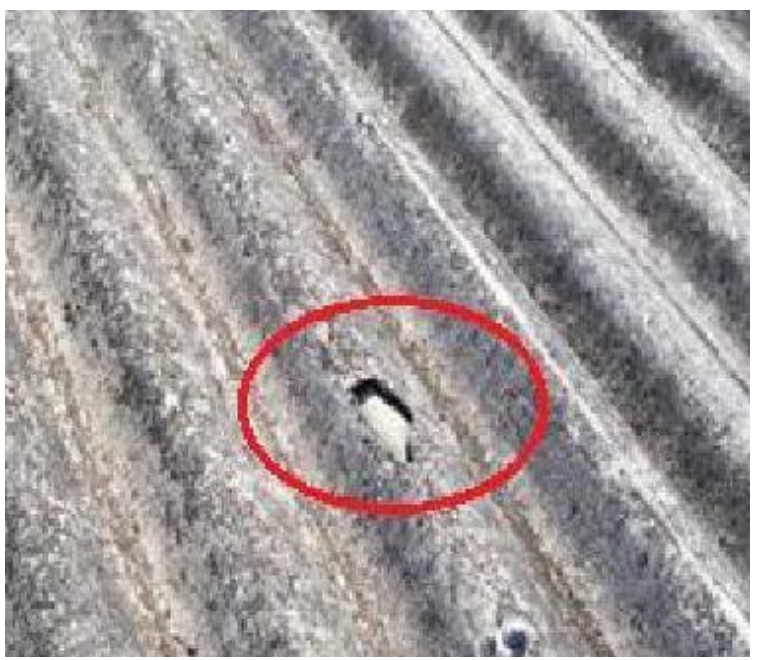

(a)

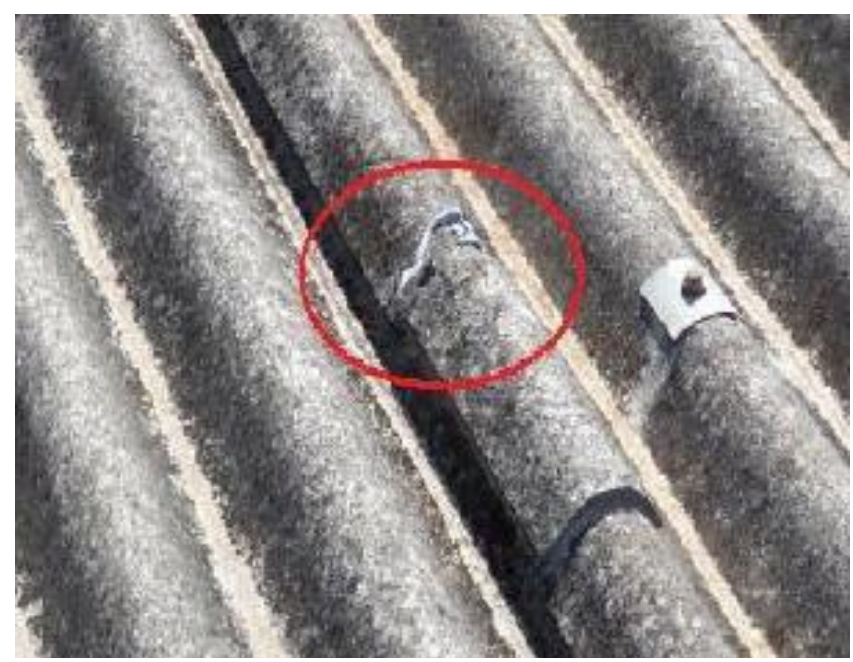

Fonte: Primeiro Autor

\subsection{Apresentação dos resultados}

Como referido anteriormente, neste artigo foram aplicados três modos de ponderação, visando qual dessas possui maior eficácia nas aplicações da norma holandesa no apoio à inspeção predial. Inicialmente, foram realizados os cálculos das ponderações por média aritmética e em relação ao custo de recuperação. Posteriormente, comparam-se estes valores entre si e com os obtidos com outro modo de ponderação, relativamente à importância.

\subsubsection{Ponderação por média aritmética (PMA)}

Para a PMA, os resultados da classificação da condição da edificação foram realizados com a somatória das médias das classificações da condição das famílias e dividida pela quantidade total de famílias. A Figura 12 mostra o gráfico que representa, em porcentagem, como cada família contribui para o grau de criticidade.

Figura 12: Peso das famílias no grau de criticidade.

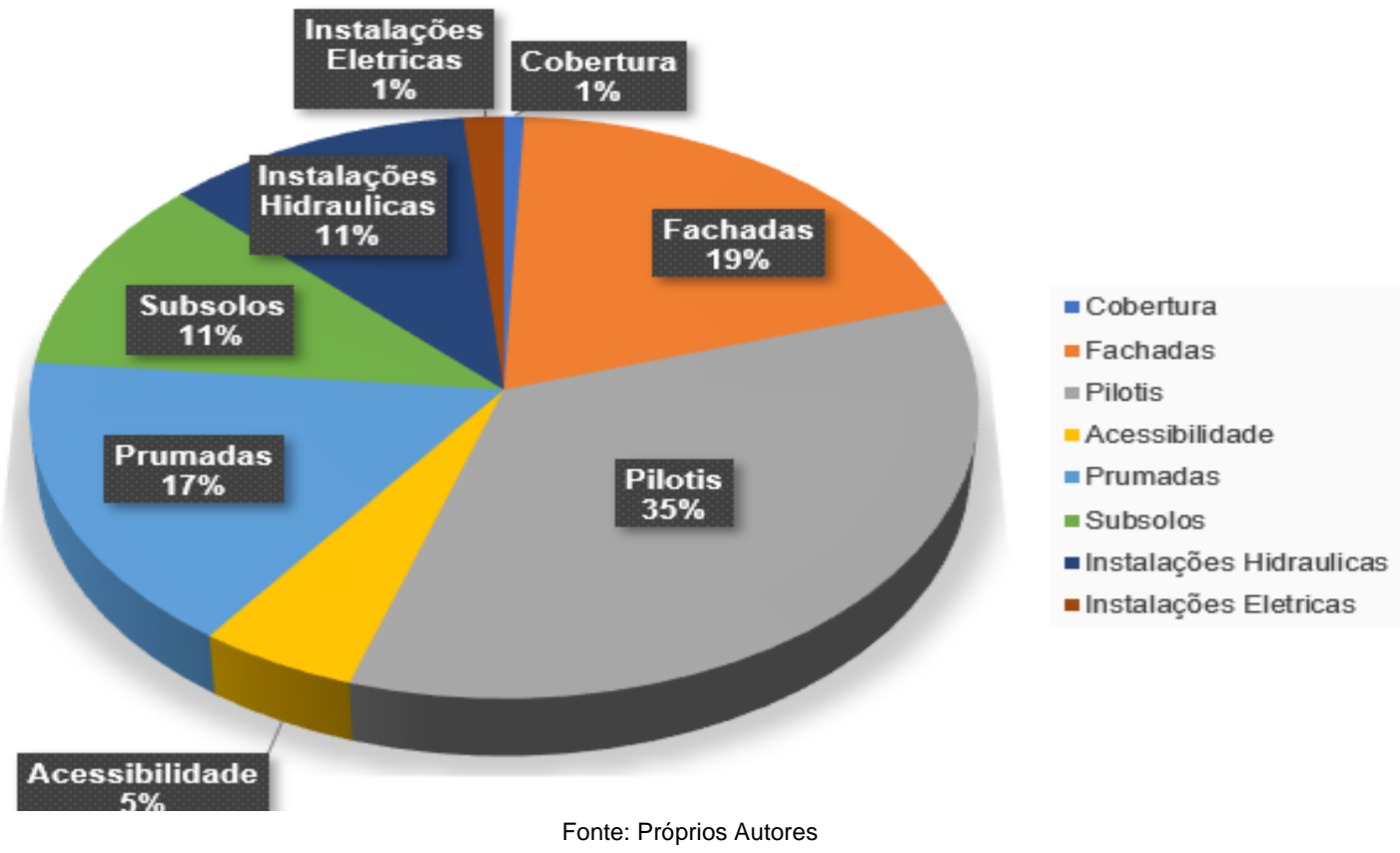




\subsubsection{Ponderação em relação aos custos (PRC)}

Usando a PRC, foi levantado o orçamento dos custos de cada elemento da edificação, a fim de encontrar o custo de cada família e o custo total. Encontrado esses valores, calcula-se o peso da família para a construção, cujo cálculo é feito com base na divisão do custo da família pelo custo total (13). Após encontrar o peso, este é multiplicado pela média da classificação da condição da família para encontrar uma nova média da família em porcentagem.

Seguindo este método, o resultado para o grau de criticidade da edificação como um todo foi de 0,42 , o que corresponde a nota "razoável" conforme estabelecido pela norma holandesa para inspeção predial.

Figura 13: Peso das famílias no grau de criticidade.

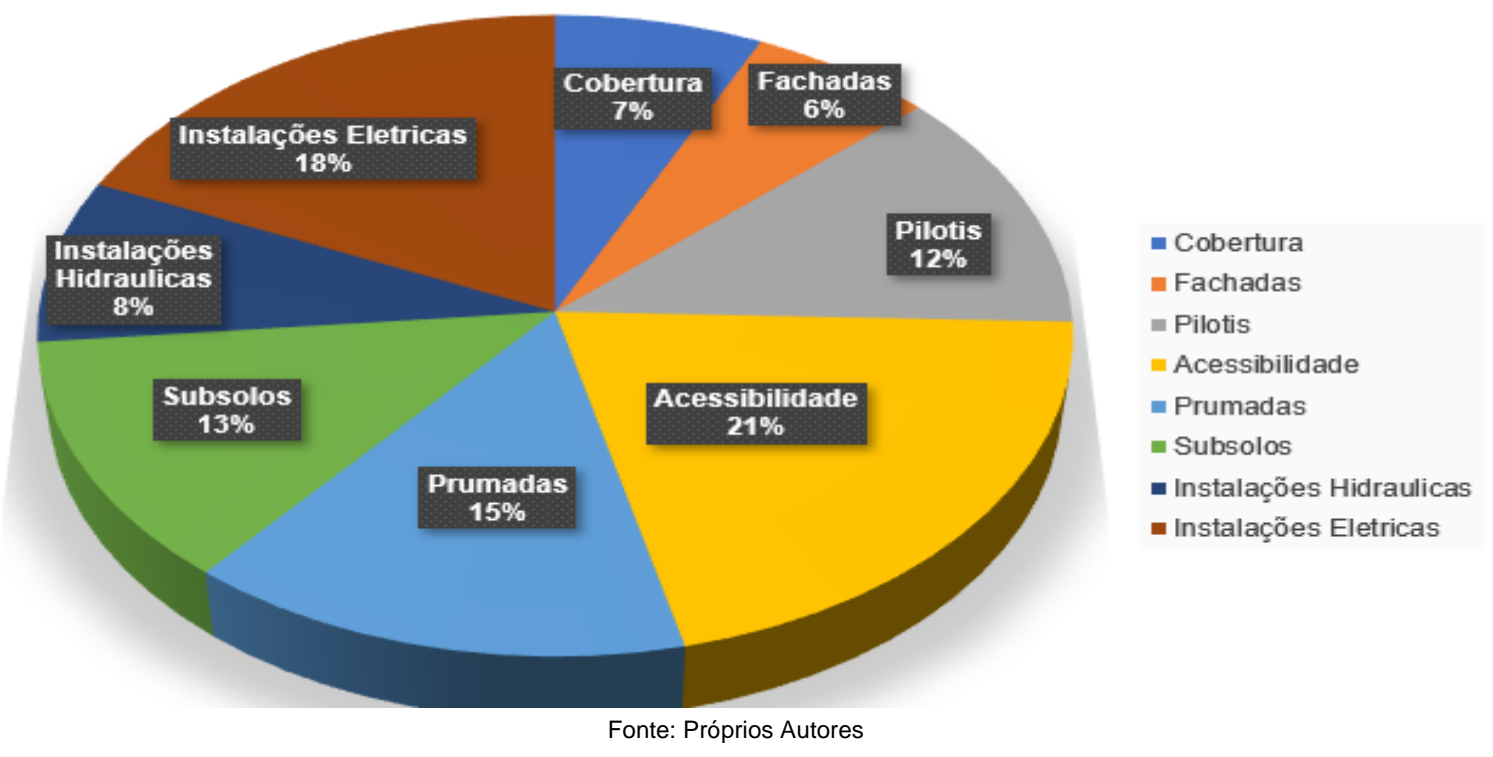

\subsubsection{Comparação de resultados entre formulações}

A comparação entre os pesos de cada família e para cada método, é apresentada no Tabela 2, que expõe os pesos utilizados nas ponderações e o grau de criticidade de cada família por método, bem como a diferença entre os graus de criticidade das famílias.

Tabela 2: Grau de criticidade.

\begin{tabular}{|c|c|c|c|c|c|c|}
\hline \multirow{2}{*}{ Família } & \multicolumn{2}{|c|}{$\begin{array}{c}\text { Ponderação em Relação } \\
\text { aos Custos (PRC) }\end{array}$} & \multicolumn{2}{|c|}{$\begin{array}{l}\text { Ponderação por Média } \\
\text { Aritmética (PMA) }\end{array}$} & \multicolumn{2}{|c|}{$\begin{array}{c}\text { Ponderação em Relação } \\
\text { à Importância (PRI) }\left(^{*}\right)\end{array}$} \\
\hline & $\begin{array}{l}\text { Peso da } \\
\text { Família }\end{array}$ & $\begin{array}{c}\text { Grau de } \\
\text { Criticidade }\end{array}$ & $\begin{array}{l}\text { Peso da } \\
\text { Família }\end{array}$ & $\begin{array}{c}\text { Grau de } \\
\text { Criticidade }\end{array}$ & $\begin{array}{l}\text { Peso da } \\
\text { Família }\end{array}$ & $\begin{array}{c}\text { Grau de } \\
\text { Criticidade }\end{array}$ \\
\hline Cobertura & 0,01 & 0,003 & 0,125 & 0,035 & 0,01 & 0,003 \\
\hline Fachadas & 0,32 & 0,08 & 0,125 & 0,031 & 0,35 & 0,088 \\
\hline Pilotis & 0,29 & 0,144 & 0,125 & 0,061 & 0,12 & 0,06 \\
\hline Acessibilidade & 0,03 & 0,021 & 0,125 & 0,104 & 0,20 & 0,166 \\
\hline Prumadas & 0,11 & 0,068 & 0,125 & 0,074 & 0,16 & 0,094 \\
\hline Subsolos & 0,09 & 0,045 & 0,125 & 0,063 & 0,12 & 0,06 \\
\hline Inst. Hidráulicas & 0,14 & 0,046 & 0,125 & 0,041 & 0,02 & 0,007 \\
\hline Inst. Elétricas & 0,01 & 0,006 & 0,125 & 0,091 & 0,02 & 0,015 \\
\hline \multirow{2}{*}{$\begin{array}{l}\text { Grau de } \\
\text { criticidade }\end{array}$} & \multirow{2}{*}{1} & 0,413 & \multirow{2}{*}{1} & 0,50 & \multirow{2}{*}{1} & 0,491 \\
\hline & & "Razoável" & & "Razoável" & & "Razoável" \\
\hline
\end{tabular}

$\left(^{*}\right)$ Valor proposto pelos Autores

Fonte: Próprios Autores

Nota-se que na PRC os custos das famílias que tiveram maior peso foram: as "fachadas", os "pilotis", as "instalações hidráulicas" e as "prumadas". Já as famílias que tiveram menor peso foram a "cobertura", o "subsolo", as "instalações elétricas" e as "acessibilidades da edificação". Seguiu-se o 
critério de custo de recuperação, por levar em conta o montante financeiro necessário para que o elemento volte a desempenhar a sua função com o mesmo desempenho que possuía aquando da sua inauguração, independentemente de sua finalidade na edificação. Esta consideração fez com que famílias de elementos onde se evidenciavam redução de desempenho no campo da estética, como no caso das famílias "fachada" e "pilotis", tivessem grande peso de ponderação por terem alto custo de recuperação. Já para outras famílias, com atribuição funcionais e com custo de recuperação mais baixos, como as instalações elétricas e hidráulicas, o "subsolo" e a "cobertura" obteve-se um peso de ponderação baixo.

Pela PMA, todas as famílias tiveram o mesmo peso da razão (1/8).

$\mathrm{Na} \mathrm{PRI}$, as escolhas de valores foram feitas de acordo com as prioridades dos moradores. Relativamente à família "fachadas" obtiveram-se relatos de, em casos de chuvas fortes, entrada de água nos apartamentos pelas esquadrias. Outra família que aumentou o seu peso foi a das "acessibilidades", pois muitos dos condôminos são idosos e isto faz com que tenha influência para aqueles que transitam frequentemente no local. As famílias "subsolo" e "prumadas" também se obviaram como prioridades, por causa das infiltrações encontradas na edificação. Os "pilotis" têm um valor menor já que as mudanças não precisam ser realizadas de forma imediata. As famílias da "cobertura", "instalações hidráulicas" e "instalações elétricas" possuem menores pesos.

A diferença encontrada entre os três modos de ponderação foi pequena e na classificação obteve-se a mesma classificação de condição: "razoável". A Figura 14 mostra as diferenças entre as famílias, em porcentagem.

Figura 14: Comparação de peso por família.

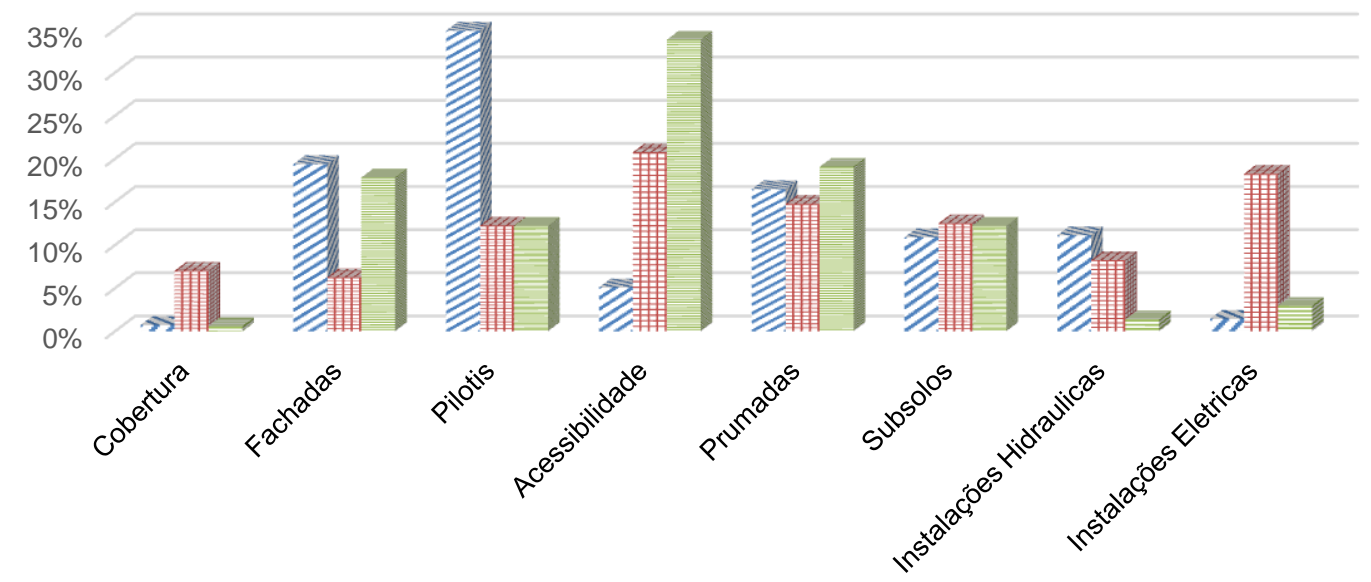

- Norma holandesa parametrizada ponderada por custo de recuperação

- Norma holandesa parametrizada média aritmática

= Norma holandesa parametrizada ponderada em relação à importância

Fonte: Próprios Autores

\section{Conclusão}

A norma holandesa para inspeção predial tem como um de seus principais objetivos auxiliar os gestores e usuários das edificações, que na maioria dos casos não possuem conhecimentos específicos na área da engenharia, na tomada de decisões no gerenciamento do patrimônio. Para muitos, o que realmente interessa é a classificação do grau de criticidade. Com o intuito do vistoriador 
gerar um laudo preciso para as necessidades do cliente, é necessário que ele entenda quais são as prioridades do uso da edificação por parte do cliente, uma vez que os critérios de ponderação podem ser amplos e, se mal utilizados, podem geram resultados distorcidos, que levarão até mesmo ao à instalação do pânico e a tomadas de decisões erradas por partes dos gestores. No caso de estudo apresentado no presente artigo, os critérios de PRC e PRI, possuem um resultado que distribui pesos diferentes para cada família, já no critério PMA distribui importâncias iguais para famílias diferentes. Os critérios de PRC e PRI são os que mostraram melhor eficiência para os vistoriadores e os condôminos na tomada de decisão.

\section{Agradecimentos}

Este trabalho foi financiado por: Financiamento Base - UIDB/04708/2020 e Financiamento programático - UIDP/04708/2020 da Unidade de Investigação CONSTRUCT - Instituto de I\&D em Estruturas e Construções - financiada por fundos nacionais através da FCT/MCTES (PIDDAC).

\section{Referências}

ASSOCIAÇÃO BRASILEIRA DE NORMAS TÉCNICAS. NBR 5674: Manutenção de Edificações Requisitos para o sistema de gestão de manutenção. Rio de Janeiro, 2012.

ASSOCIAÇÃO BRASILEIRA DE NORMAS TÉCNICAS. NBR 9050: Adequação das edificações e do mobiliário urbano à pessoa deficiente - Procedimento. Rio de Janeiro, 1985.

EUROPEAN COMMITTEE FOR STANDARDIZATION. CEN, EN 13306 Maintenance Terminology. Brussels, 2001.

HORNER, R.M.W.; EL-HARAM; M.A.; MUNNS, A.K. Building maintenance strategy: A new management approach. Journal of Quality in Maintenance, Vol. 3, N. 4, 1997.

MOURA, T.J.M. Metodologia de avaliação do estado de conservação do edificado. 214 páginas, 2014. Dissertação de Mestrado em Engenharia Civil - Departamento de Engenharia Civil, Universidade de Aveiro, Aveiro.

NATÁRIO, A.L.R. Modelo de gestão da manutenção em edifícios da Santa Casa da Misericórdia de Lisboa: Indicadores de desempenho da manutenção de edifícios. 2016. 86 páginas. Dissertação de Mestrado em Construção e Reabilitação - Instituto Superior Técnico, Universidade Técnica de Lisboa, Lisboa.

NEDERLANDS NORMALISATIE INSTITUUT. NEN 2767: Conditiemeting van bouw - en installatiedelen - Deel 1: Methodiek. Holanda, 2006.

PEDRO, J.B.; VILHENA, A.; PAIVA, J.V. Métodos de avaliação do estado de conservação de edifícios desenvolvidos no LNEC: Características e possibilidades de aplicação. Engenharia Civil. Universidade do Minho, Vol. 42, pp. 5-18, 2012.

PITT, T.J. Data requirements for the prioritization of predictive building Maintenance. Facilities, Vol. 15, N. 3-4, pp. 97-104, 1997.

STRAUB, Ad. Dutch standard for condition assessment of buildings. Structural Survey, Vol. 27, pp. 2335, 2009 .

VILHENA, A.J.D.S.M. Método de avaliação do estado de conservação de edifícios: Análise e contributos para o seu aperfeiçoamento e alargamento do âmbito. 364 páginas, 2011. Tese de Doutoramento em Engenharia Civil - Instituto Superior Técnico, Universidade Técnica de Lisboa, Lisboa. 